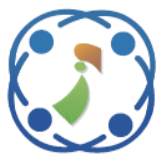

\title{
Voltage Deviation Minimization of Grid Connected Wind Generation System Using Hybrid PI-Fuzzy Logic Controller Based Static Var Compensator
}

\author{
Istiyo Winarno ${ }^{1,2 *}$ \\ Mochamad Ashari ${ }^{1}$ \\ Heri Suryoatmojo ${ }^{1}$ \\ ${ }^{1}$ Department of Electrical Engineering, Faculty of Electrical Technology, \\ Institut Teknologi Sepuluh Nopember, Surabaya, Indonesia \\ ${ }^{2}$ Department of Electrical Engineering, Faculty of Engineering and Marine Science, \\ Universitas Hang Tuah, Surabaya, Indonesia \\ * Corresponding author's Email: istiyo.winarno@gmail.com
}

\begin{abstract}
This paper proposed a Hybrid PI-Fuzzy based Static Var Compensator for minimizing voltage deviations as the integration of wind power generation to the distribution network. Hybrid PI-Fuzzy Logic controller constructed by the cascade-connected conventional PI controller and Fuzzy Logic controller. This algorithm combined the advantages and minimized the disadvantages of each conventional controller. The control method applied to the Static Var Compensator, which functioned as a dynamic reactive power source. The controlled dynamic reactive power source influenced the system with proper reactive power value, which resulted in the voltage regulation. Two scenarios were carried out to investigate the efficacy of the proposed method. The first scenario demonstrates the performance of the proposed system in wind speed variations and the second scenario in load variation conditions. Finally, the comparisons with Fuzzy Logic Controller-based self-tuning PI control were made to investigate the performance of the proposed control method. Simulation results verified that the proposed control algorithm outperformed the FLCbased self-tuning PI controller, in terms of the steady-state voltage deviation minimization by $1.47 \%$ and the settling time of the voltage respond decrement by $92.78 \%$.
\end{abstract}

Keywords: Voltage deviation, Wind generation, Power system grid, Static var compensator, Reactive power, Hybrid PI-fuzzy logic controller.

\section{Introduction}

Wind power had played an important role in global renewable energy development these last three decades. Its accounted as the second place of world total renewable power capacity right after hydropower in 2017. Wind power had drawn 539 GW of 2,195 GW world total renewable power capacity. In majority cases, the wind powers are integrated into the existing power system grid [1]. Unfortunately, the increasing integration of this power generation into the power system grid possesses some serious challenges related to the voltage deviation problem, besides systems stability and reliability, as already discussed in [2-4].

The voltage deviation problem could be mitigated by managing the reactive power of the systems, by means choosing proper capacitor compensation capacity or installing a dynamic reactive power compensation device [5,6]. Brief reviews of the conventional volt/var control algorithm for regulating the voltage deviation in the distribution system, as the effect of output power fluctuations are discussed in [7-9]. This strategy could improve the control abilities of the wind power system not only producing active power but also producing/consuming the reactive power to or from the grid. Besides the methods discussed in the articles, these past few years, the flexible alternating current transmission system (FACTS) devices have enticed the researcher to utilize them to solve this problem. For example, in [10], the enhancement of voltage regulation capability is analyzed by installing a static synchronous compensator (STATCOM) system, parallel-connected with the DFIG-based wind generation system. Another example, in [11], the 
authors demonstrated the contribution of Distribution-STATCOM (D-STATCOM) for increasing the voltage stability margin of gridconnected DFIG-based wind power plants.

This paper proposed the enhancement of voltage regulation capability of the grid-connected wind power plant using a Hybrid PI-Fuzzy Logic Controller based Static Var Compensator (SVC). SVC is one of the shunt-connected types of FACTS devices that have an important function in voltage stability and voltage regulation of the electric power system. The voltage regulation could be carried out by SVC by absorbing or injecting reactive power sufficiently [12]. SVC is made up of individual basic types of reactive power compensators or a combination of it. The individual basic type of SVC includes Saturated Reactor (SR), ThyristorControlled Reactor (TCR), Thyristor-Controlled Transformer (TCT), and Thyristor-Switched Capacitor (TSC). Moreover, Fixed CapacitorThyristor-Controlled Reactor (FC-TCR), Mechanically Switched Capacitor-ThyristorControlled Reactor (MSC-TCR) and ThyristorSwitched Capacitor-Thyristor-Controlled Reactor (TSC-TCR) are the example of the combination types of SVC [13].

SVC's conventional control algorithm needs to be modified to enhance its capabilities. Authors in [1421] have made the modifications using intelligent control systems. In [14, 15], the effectiveness and capabilities of the SVC were enhanced by integrating Fuzzy Control (FC) to the conventional controller. By this integration, the performance of SVC in transient and steady-state conditions could be improved. In [16], a control strategy is designed by tuning the control parameter of a conventional PID controller with FC. This control algorithm could comply with the better performance and stability requirements of SVC. In [17], two control methods are implemented for different purposes. The first control method is the instantaneous power theory, which designed for the open-loop system. The second control method is the fuzzy proportional-integraldifferential control strategy, which implemented in the closed-loop system. The results of these control strategies show that SVC has a good performance both in static and dynamic conditions. The author in [18] proposed an adaptive fuzzy logic scheme based SVC, which is developed based on the energy descent concept to improve the system performance. The author in [19] stated that the use of the adaptive-fuzzy controller for SVC could address the oscillation problem in the wind energy conversion system (WECS). The proposed controller composed of a radial basis function neural network, which performs the prediction state and a neuro-fuzzy inference system as a primary controller, which offers the damping signal. The SVC capabilities in an electric power system with integration of wind turbine was studied in [20,21]. The stability of the system was enhanced by implementing an adaptive networkbased fuzzy inference system (ANFIS). The strategy proposed in these studies gives possibilities to the SVC to control the voltage stability of the electric power system. ANFIS control strategy could show the captivating performance, especially in fast response and accuracy. However, it needs some experience to design it, because this control strategy is more complicated, compared with other intelligent control system based on basic fuzzy systems [21].

This work evaluates the effectiveness of SVC for voltage deviation minimization in a power grid with the integration of wind energy power systems. In this case, the SVC unit formed by one TCR unit and three TSC units. The capabilities of the SVC enhanced by utilizing a Hybrid PI-Fuzzy Logic Controller (HPIFLC). The control strategy developed by combining the conventional Proportional and Integral (PI) controller and Fuzzy Logic Controller (FLC). The two controllers connected in cascade connection mode. Therefore, using the HPI-FLC for SVC control strategy aim to the regulating of the system voltage. In other words, the voltage deviation will be minimized, in spite of the wind speed variations and the load fluctuations, within the permissible range. Moreover, the SVC control strategy proposed in this paper demonstrates effectively for minimizing voltage deviation, compared with previous control methods, FLC-based self-tuning PI controller (FSTPI) $[16,22]$.

The structure of this paper is described as follows. Section 2 discusses the detailed concept of voltage control strategy using the proposed control algorithm. The simulation scenarios, results, and discussion are presented in section 3. Finally, section 4 concludes the effectiveness of the proposed methods.

\section{Configuration of hybrid PI-fuzzy logic controller based static Var compensator}

The representation of the proposed systems configuration depicted in Fig. 1, which used to study the voltage behavior of grid-connected wind power generation systems. The wind power system was constructed from 2 units of $1.5 \mathrm{MW}$ Induction Generator based wind generation, the line to line voltage rated at $380 \mathrm{~V}$ and operated at $50 \mathrm{~Hz}$. The 3 MW wind generation system was connected to $12 \mathrm{kV}$ bus through a $4 \mathrm{MVA}$ power transformer rated at $0.380 \mathrm{kV}$ Y/12 kV Y and $1 \mathrm{~km}$ three-phase pi-section 


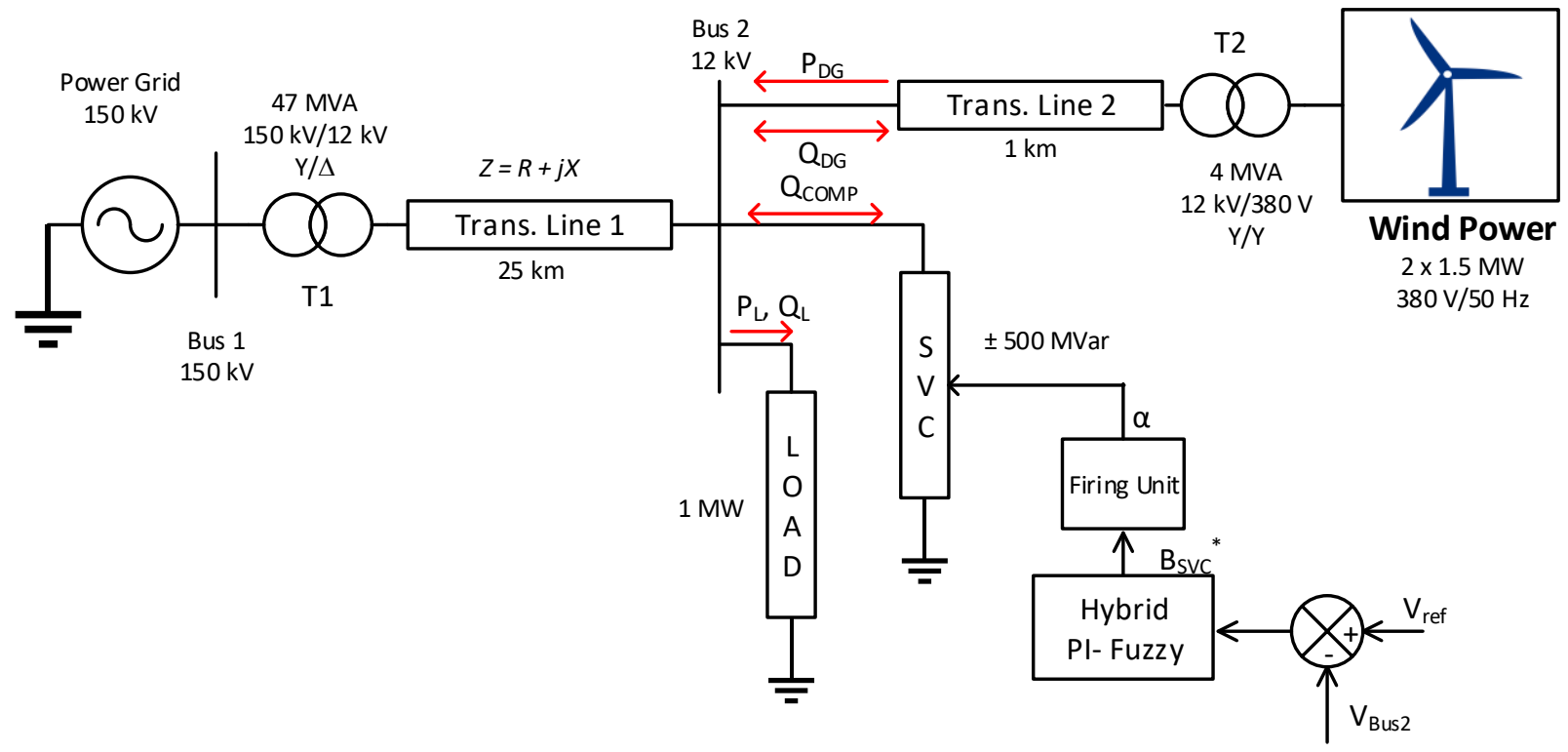

Figure.1 Proposed systems configuration

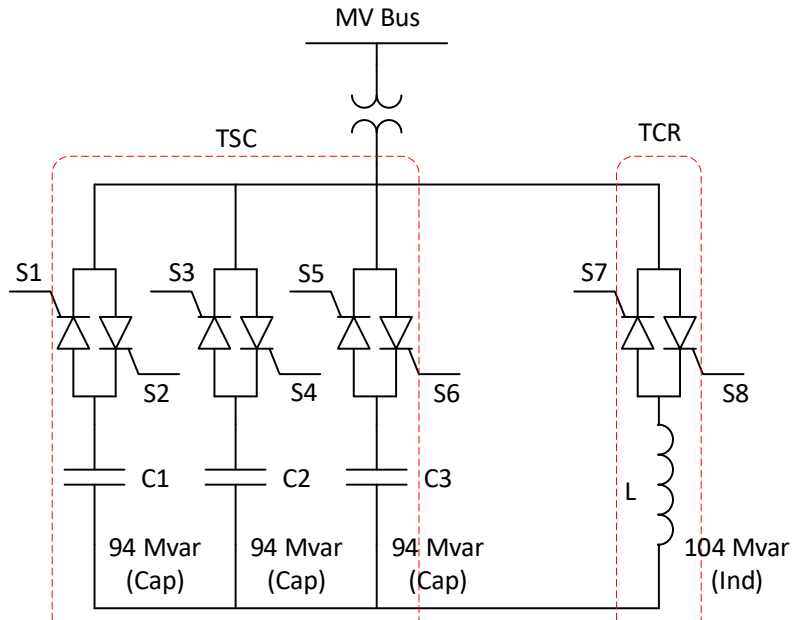

Figure.2 TSC-TCR configuration

transmission line. It was in line with $1 \mathrm{MW}$ resistive load and SVC. The SVC designed with a combination of three Thyristor-Switched Capacitor (TSC) banks and a single Thyristor-Controlled Reactor (TCR) that are connected in parallel, which commonly called TSC-TCR, as depicted in Fig. 2.

The distance between $12 \mathrm{kV}$ bus and the power grid bus was $25 \mathrm{~km}$. The $150 \mathrm{kV}$ power grid delivered the power to $12 \mathrm{kV}$ bus through a power transformer, which rated at $47 \mathrm{MVA}$ and $150 \mathrm{kV} \mathrm{Y/12} \mathrm{kV} \Delta$. The parameters of three-phase pi-section lines were stated at $0.1153 \Omega / \mathrm{km}, 1.05 \mathrm{mH} / \mathrm{km}$ and $11.33 \mu \mathrm{F} / \mathrm{km}$ for positive sequence of resistance, inductance, and capacitance. A detailed explanation of the proposed control algorithm is presented in the following subsections.

The verification of the proposed control algorithm made by comparing it with the previous control technique, namely FST-PI [16,22]. A brief theoretical explanation about this algorithm discussed in the following subsections.

\subsection{The basic concept of SVC-based voltage control strategy}

As discussed in the introduction, the SVC-based reactive power control algorithm proposed for the voltage control strategy. The SVC was originally designed for reactive power compensator, but it also has the capability of voltage control. The voltage control capability achieved by proper management of active and reactive load and generation, as depicted in Fig. 1, which illustrated the dependencies of voltage and several variables in the distribution network. The voltage at Bus 1 in Fig. 1 can be calculated as:

$$
V_{B u s 1} \approx V_{B u s \_2}+I_{B u s_{-} 2} \cdot Z
$$

or

$$
V_{\text {Bus1 }} \approx V_{\text {Bus } 2}+I_{\text {Bus2(Real) }} R+I_{\text {Bus2(Imag) }} X
$$

where

$$
I_{\text {Bus2(Real) }}=\frac{P_{D G}-P_{L}}{V_{B u s 2}}
$$

and

$$
I_{B u s 2(\text { Imag })}=\frac{ \pm Q_{D G} \pm Q_{C o m p}-Q_{L}}{V_{B u s 2}}
$$

$V_{B u s 1}$ and $V_{B u s 2}$ are voltage at Bus 1 and Bus 2, respectively. $I_{B u s 2(R e a l)}$ is the real current which flows in Bus 2, and $I_{B u s 2(R e a c t)}$ is the Bus 2's 
reactive current. $P_{D G}$ and $Q_{D G}$ are active and reactive power of local distributed generation, which parallelconnected with local load, with $P_{L}$ and $Q_{L}$ contribution, and SVC. Reactive power compensation, $Q_{\text {Comp }}$ is supplied from $\mathrm{SVC}$, as a reactive compensator. Therefore, bus voltages can be regulated by controlling P and Q [23].

The voltage control capability of the SVC can be described in a simplified diagram, which represents the SVC and power system network, as depicted in Fig. 3 (a). An equivalent voltage source, VS, represents the power generation system and XS models and equivalent system impedance. The SVC bus voltage is formulated by:

$$
V_{S}=V_{S V C}+I_{S V C} X_{S}
$$

where $I_{S V C}$ is a reactive current drawn by SVC, as illustrated in Fig. 3 (b). The voltage-control behavior is expressed as:

$$
V_{S V C}=V_{\text {ref }}+X_{S L} I_{S V C}
$$

where $X_{S L}$ is the ratio of voltage change to the current change of the compensator. The reactive current, $I_{S V C}$, will be positive if SVC more inductive and negative if more capacitive. Thus, the SVC bus voltage will decrease when the SVC draws inductive current and increase when SVC draws capacitive current [13].

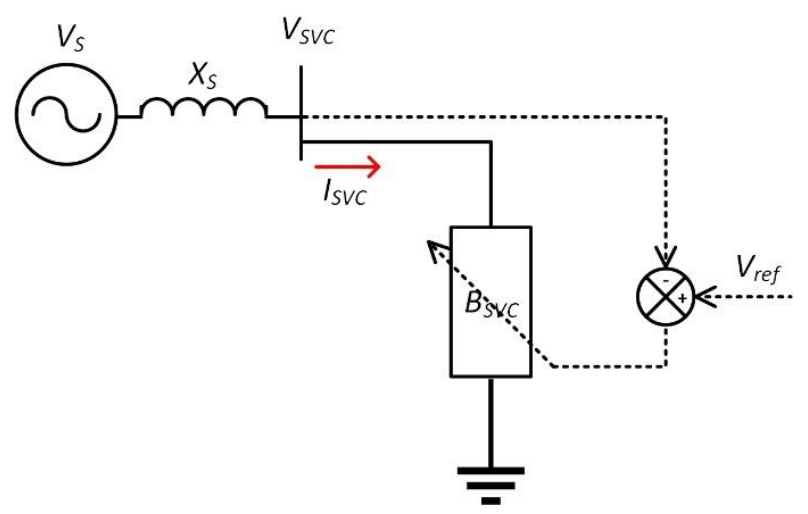

(a)

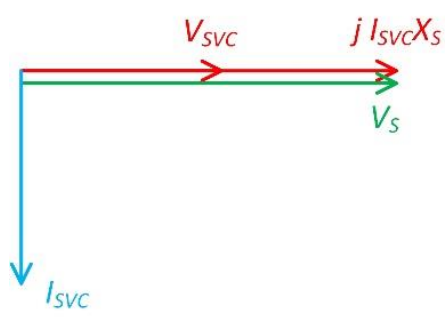

(b)

Figure.3 Simplified diagram: (a) The equivalent power system with SVC control algorithm and (b) Phasor diagram of the power system with the presence of SVC
Handling a linearization operation to Eq. (5) provides the variation of the $V_{S V C}$ as a linear function of the SVC current change, $I_{S V C}$. Hence,

$$
\Delta V_{S V C}=-X_{S} \Delta I_{S V C}
$$

assuming equivalent source voltage, $V_{S}$, in a constant value. The $V_{S V C}$ also could be associated with $I_{S V C}$ over the SVC susceptance, $B_{S V C}$, as formulated below:

$$
I_{S V C}=B_{S V C} V_{S V C}
$$

or

$$
V_{S V C}=\frac{I_{S V C}}{B_{S V C}}
$$

or in other words, $V_{S V C}$ is inversely proportional to $B_{S V C}$. As discussed before, the selected type of SVC is TSC-TCR. For this type of SVC, the total susceptance, $B_{S V C}$, expressed as:

$$
B_{S V C}=B_{C 3}+B_{T C R}
$$

where $B_{C 3}$ is the total susceptance of 3 TSC branches, expressed as:

$$
B_{C 3}=\omega C_{1}+\omega C_{2}+\omega C_{3}
$$

and $B_{T C R}$ is the susceptance of the TCR branch which formulated as:

$$
B_{T C R}=\frac{2 \pi-2 \alpha+\sin 2 \alpha}{\pi}
$$

where $\alpha$ is the firing angle of the thyristor. The $B_{S V C}$ will be assigned negative values if it is inductive susceptance, and will be assigned positive values if it is capacitive susceptance [13].

\subsection{Hybrid PI-fuzzy logic control algorithm}

The bus voltage regulation could be achieved by controlling the firing angle of the compensator, $\alpha$, in order to obtain the proper value of compensator's susceptance, $B_{S V C}$. This paper proposed a combination of two control strategies, the Proportional and Integral (PI) controller and the Fuzzy Logic Controller (FLC), to handle the control action of the system. This combination is defined as Hybrid PI-Fuzzy Logic Controller (HPI-FLC). The HPI-FLC composed of the simple PI controller and FLC, which connected in cascade mode. Fig. 4 depicts this configuration. The input parameter 


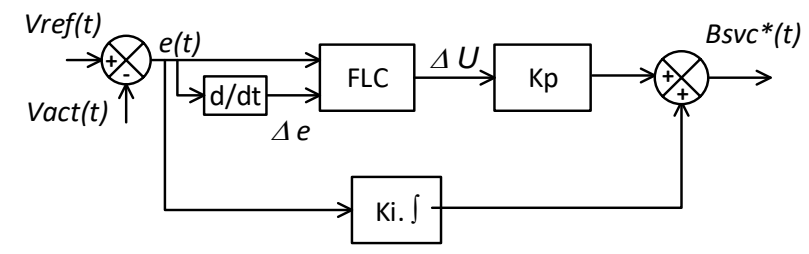

Figure.4 Concept of hybrid PI-fuzzy logic controller

consists of two variables. The first variable is the difference between reference and actual value, which known for error. And the second variable is the error change or known as derivative error. The HPI-FLC could be mathematically expressed as:

$$
B_{S V C}{ }^{*}(t)=\Delta U . K p+K i \int e(t) d t
$$

where $\Delta U$ is the output state of FLC, $K p$ is the proportional gain, $K i$ is the integral gain, and $e$ is the error of systems' voltage.

The logic of the control algorithm could be described as follows: if the difference of actual value and the reference value is large then the Fuzzy Logic control will react to the uncertain parameters of the systems, whereas, the PI controller will reduce the static error of the system if the difference is small. The control algorithm has several advantages, such as providing the parameters of the PI controller and the selection of fuzzy membership function properly; therefore, the controller will result in a precise response, better than PI or fuzzy controller, which utilized individually [24].

The PI controller, in this application, was employed to determine the reference value of SVC's susceptance. Its parameters were tuned firstly before being combined with the FLC. The tuning procedure was using the trial and error method. The parameter values were 10 for the proportional gain $(\mathrm{Kp})$ and 200 for the integral gain (Ki).

Meanwhile, the FLC design procedure will be explained as follows. Generally, the FLC design procedure divided into three steps. The first step is the initialization of the input and output, corresponding to the implementation. In this paper, the FLC is designed to enhance the PI controller performance in stabilizing and minimizing the system voltage. Therefore, the system voltage error and its derivative are stated as the FLC input, and the output is an auxiliary signal that dynamically changes the signal input of the proportional part of the PI controller.

The second step of the FLC design procedure is the proper selection of membership functions (MF). In this work, MF for two inputs and one output parameters used Gaussian type, because of its capability to respond to the small variations of a control signal. Therefore, this Gaussian MF could give an excellent response to the small disturbances that occurred in the systems. Proper MF needs an appropriate range of FLC variables. The first input parameter of FLC, the voltage error, is set between 0.1434 and 5.329; as a result of the simulation, that this range can address the possible variations in this work. The second input parameter, the derivative of voltage error, is set between -0.0275 and 4.8693 . This value is obtained based on the simulation process. The output parameter considered between 0 and 1 as the range of multiplier for refining the performance of proportional gain.

The MFs of the FLC are illustrated in Fig. 5. Where NB is a representation of "Negative Big", NS is "Negative Small", ZZ is "Zero", PS is "Positive Small" and PB is the symbol for "Positive Big".

The third step of the FLC design procedure is the determination of the fuzzy rules. In this work, the rules determined based on the characteristic of the proportional gain of the PI controller. For example, if the voltage error is NB (small deviation between measured voltage and voltage reference) and its derivative is NB (small voltage variation), then the multiplier signal should obtain the small value, so the proportional gain only needs a small multiplication. The other fuzzy rules could be explained with a similar description. Table 1 detailed all the 25 fuzzy rules.

The output HPI-FLC delivered to the firing angle unit, which generates an appropriate firing angle, $\alpha$, for the SVC unit. Consequently, the SVC unit will generate an appropriate susceptance, $B_{S V C}$, for the network systems.

\subsection{FLC-based self-tuning PI control algorithm}

The control parameters of the conventional PI controller, namely $k p$ for the proportional part and $k i$ for the integral part, are set in fixed value. When the system encounters the unpredicted and uncertain disturbances, the performance of the conventional PI controller will be decreased. Hence, these control parameters need adjustment [16]. One of the adjustment methods had been proposed in [22]. An FLC-based self-tuning PI control algorithm could an appropriate as:

$$
B_{S V C}{ }^{*}(t)=X_{1} L_{1} e(t)+X_{2} L_{2} \int e(t) d t
$$

where $X_{1}$ and $X_{2}$ are the output parameters of the FLC, $L_{1}$ and $L_{2}$ are the learning rate of PI parameters, and $e$ is the error state of the system, as depicted in Fig. 6. The PI control parameter adaptively adjusts by the 
FLC, according to the disturbance that suddenly occurred in the system.

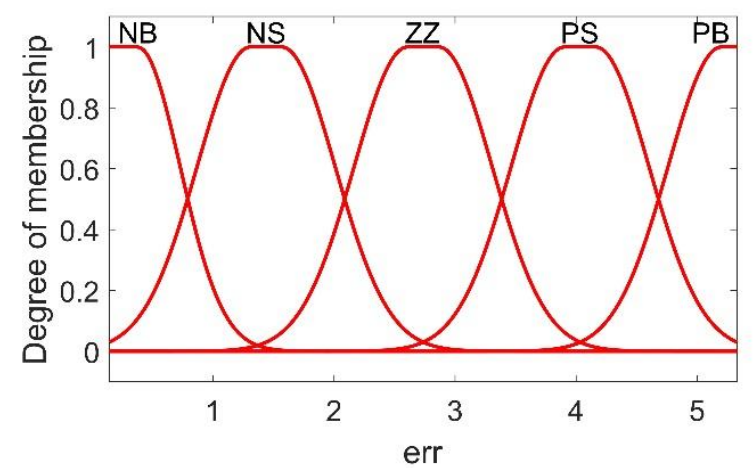

(a)

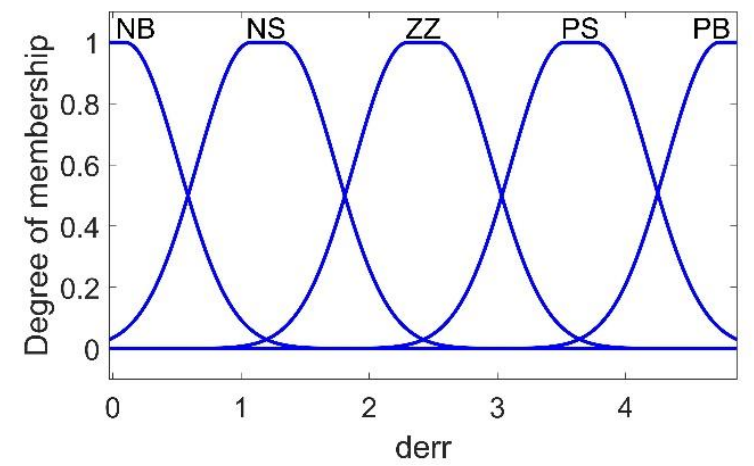

(b)

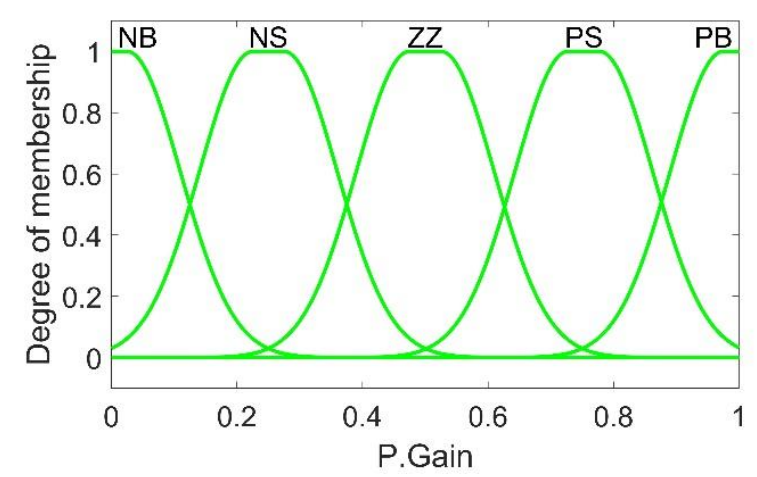

(c)

Figure. 5 Membership functions of the proposed FLC: (a) membership functions of error voltage as first FLC input, (b) membership functions of derivative of error voltage as second FLC input, and (c) membership functions of the proportional gain multiplier as FLC output

Table 1 . The fuzzy logic rule base

\begin{tabular}{|c|c|c|c|c|c|c|}
\hline & & \multicolumn{5}{|c|}{$V_{\text {BUS }}$ error } \\
\hline \multirow{6}{*}{ 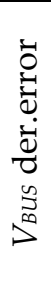 } & & NB & NS & $\mathrm{ZZ}$ & PS & PB \\
\hline & NB & NB & NB & NS & NS & $\mathrm{ZZ}$ \\
\hline & NS & NB & NS & NS & $\mathrm{ZZ}$ & PS \\
\hline & $\mathbf{Z Z}$ & NS & NS & $\mathrm{ZZ}$ & PS & PS \\
\hline & PS & NS & $\mathrm{ZZ}$ & PS & PS & PB \\
\hline & PB & $\mathrm{ZZ}$ & PS & PS & $\mathrm{PB}$ & $\mathrm{PB}$ \\
\hline
\end{tabular}

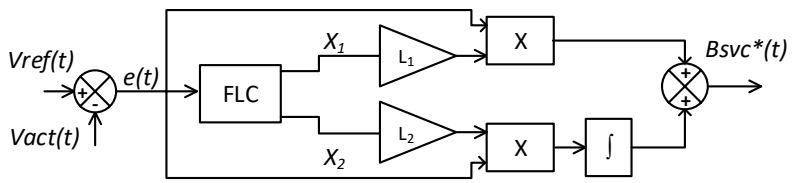

Figure.6 Concept of FLC-based self-tuning PI control

Table 2. Linguistic term of the membership

\begin{tabular}{|l||c|c|}
\hline \multirow{2}{*}{\multicolumn{1}{|c||}{ Linguistics }} & \multicolumn{2}{c|}{ Range } \\
\cline { 2 - 3 } & Min & Max \\
\hline \hline Zero & 0.0 & 0.2 \\
\hline Small & 0.3 & 0.7 \\
\hline Large & 0.8 & 1.0 \\
\hline
\end{tabular}

In this case, the fuzzy rule base which applied for PI's control parameters are could be described as:

1. If $|e(t)|$ is zero, then $K p$ is large and $K i$ is small.

2. If $|e(t)|$ is small, then $K p$ is large and $K i$ is zero.

3. If $|e(t)|$ is large, then $K p$ is large and $K i$ is large. Table 2 explained the linguistic term of the membership.

\section{Simulation scenarios, results, and discussions}

This section details the simulation scenarios, present the results and discuss them. The scenario consists of two different events. The first is the event of wind speed variations and the second is the event of load variations.

The wind speed variations scenario could be explained as follows. There are three variations of the wind speed that will be made for investigating the effectiveness of the proposed control strategy. First, the wind speed increased from $7.5 \mathrm{~m} / \mathrm{s}$ to $10.3 \mathrm{~m} / \mathrm{s}$. Second, the wind speed decreased from $10.2 \mathrm{~m} / \mathrm{s}$ to $6.0 \mathrm{~m} / \mathrm{s}$. And the third one is the increasing of the wind speed from $7.2 \mathrm{~m} / \mathrm{s}$ to $10.2 \mathrm{~m} / \mathrm{s}$. The wind speed data based on the Indonesian Meteorological, Climatological, and Geophysical Agency (BMKG) data. All three variations are simulated separately. The wind speed transition occurs at $70 \mathrm{~s}$.

Bus-2 voltage response comparison of the power system with no SVC installed, using the FST-PI based SVC and the proposed HPI-FLC based SVC with wind speed variations 1,2 , and 3 are presented in Fig. 7. Corresponding to the figure, the proposed HPI-FLC based SVC has enhanced the performance of SVC that yields in minimizing the steady-state voltage deviation of the bus and the settling time respond. Tables 3 and 4 present the numerical information, according to Fig. 7.

From Table 3, it could be clarified that the proposed HPI-FLC based SVC has been able to minimize the steady-state voltage deviation of Bus 2 
by $1.19 \%, 1.79 \%$ and $1.19 \%$ for wind speed transition 1, 2 and 3, respectively. Then, from Table 4 could be explained that the proposed control system could decrease the settling time respond by $80.30 \%$ for wind speed transition 1, 95.53\% for wind speed transition 2, and $82.92 \%$ for wind speed transition 3 .

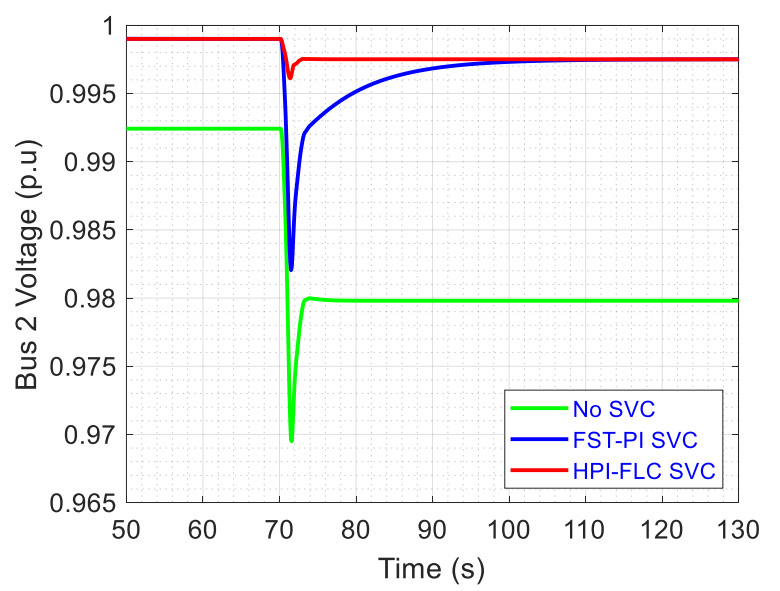

(a)

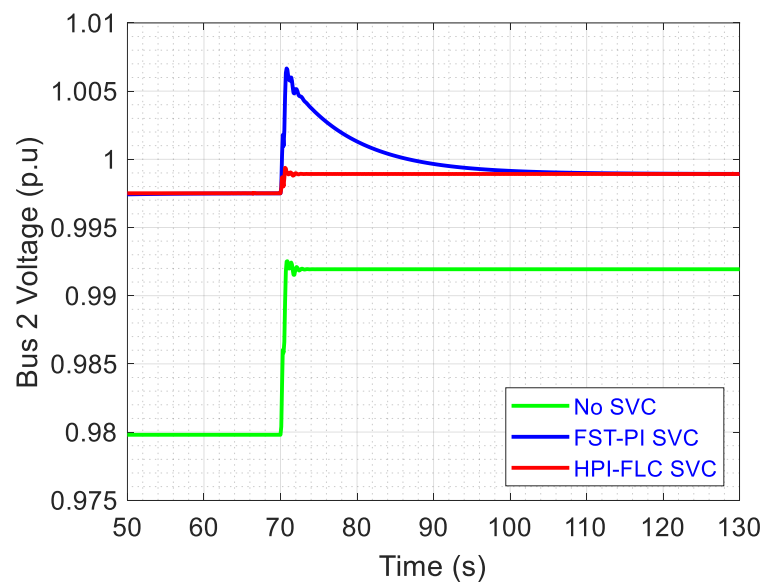

(b)

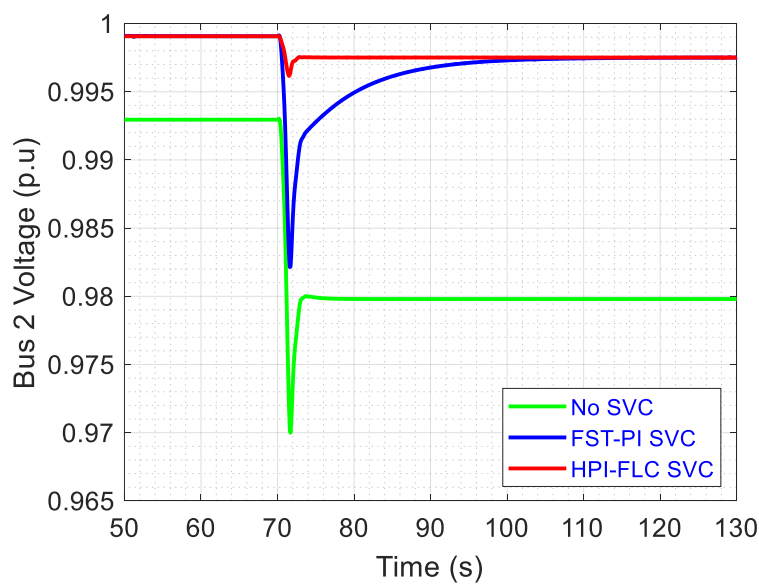

(c)

Figure. 7 Voltage response at Bus 2 for the system without SVC, with FST-PI SVC and HPI-FLC SVC: (a) with $1^{\text {st }}$ wind speed transition, (b) with $2^{\text {nd }}$ wind speed transition, and (c) with $3^{\text {rd }}$ wind speed transition
The susceptance reference variations comparison of the HPI-FLC based SVC and FST-PI based SVC is shown in Fig. 8, which represents how the HPIFLC based SVC gives results the better performance.

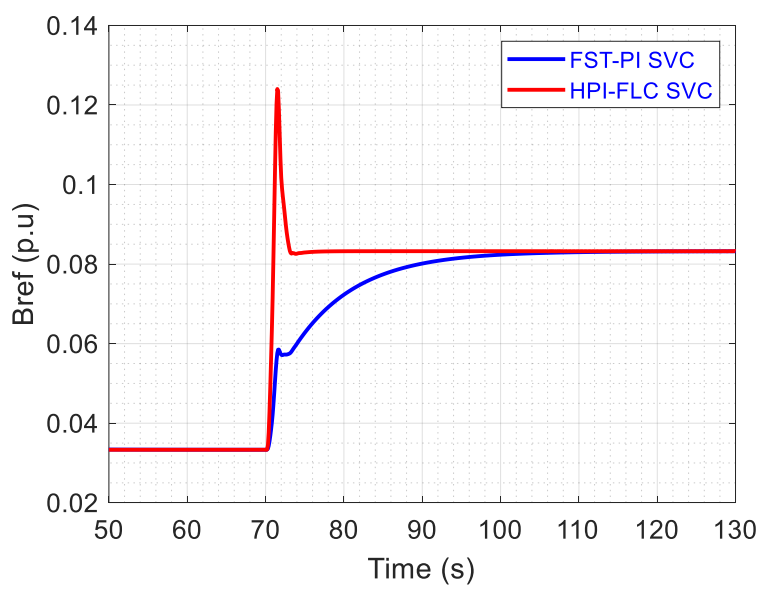

(a)

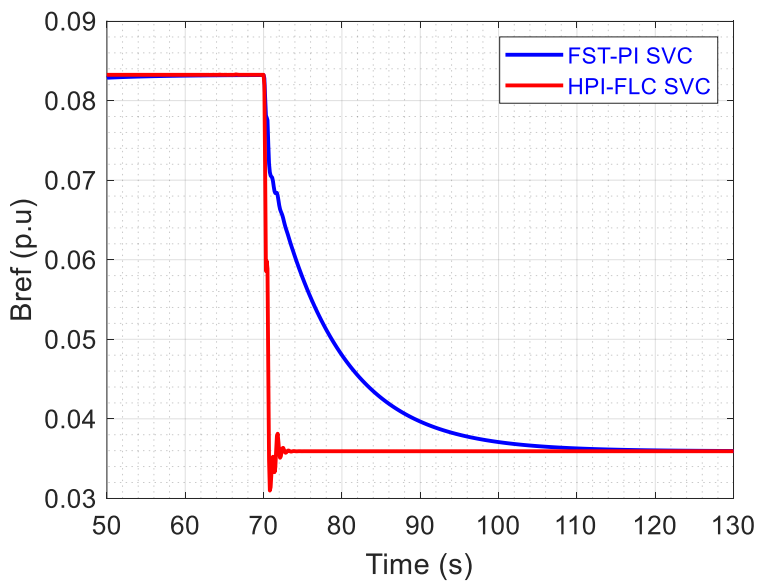

(b)

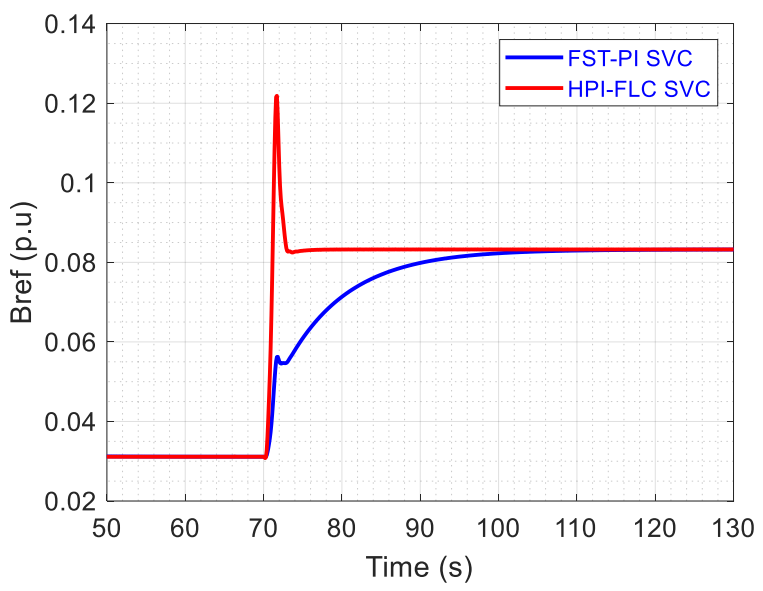

(c)

Figure. 8 Susceptance reference using FST-PI SVC and HPI-FLC SVC: (a) with $1^{\text {st }}$ wind speed transition, (b) with $2^{\text {nd }}$ wind speed transition, and (c) with $3^{\text {rd }}$ wind speed transition 


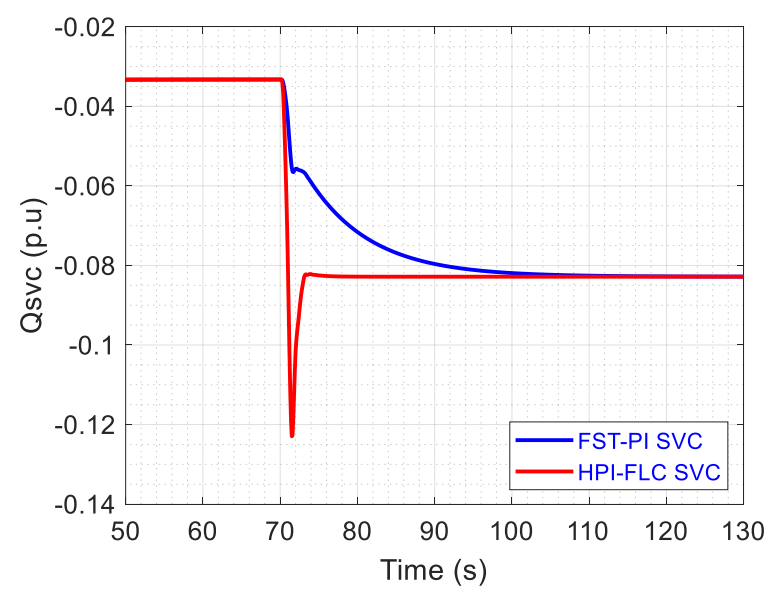

(a)

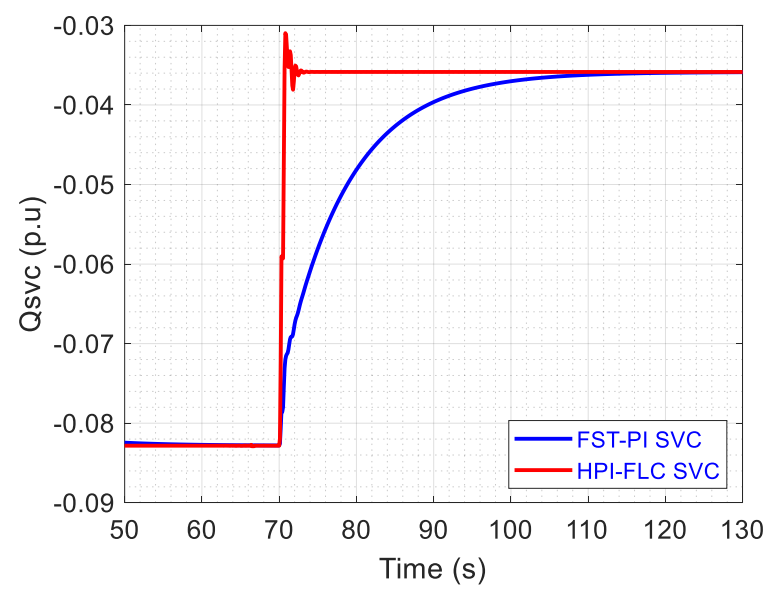

(b)

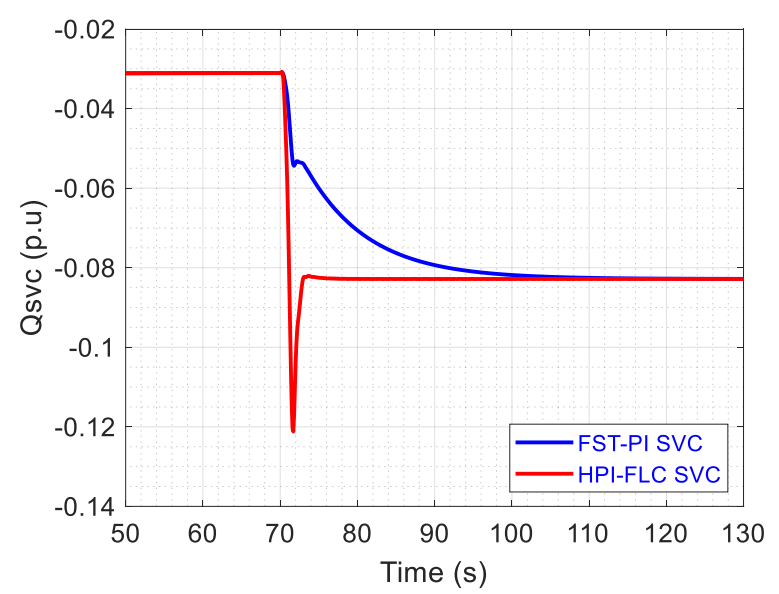

(c)

Figure. 9 Reactive power compensation using FST-PI

SVC and HPI-FLC SVC: (a) with $1^{\text {st }}$ wind speed transition, (b) with $2^{\text {nd }}$ wind speed transition, and (c) with $3^{\text {rd }}$ wind speed transition

Fig. 9 depicts the comparison of reactive power injected or absorbed by the two controls method, during the wind speed transitions.

Regarding Fig. 7, Fig. 8, and Fig. 9, the response of the system with the proposed HPI-FLC based SVC
Table 3. Voltage deviation comparison between systems without SVC, with FST-PI and HPI-FLC

\begin{tabular}{|l|c|c|c|}
\hline $\begin{array}{c}\text { Control } \\
\text { Type }\end{array}$ & $\begin{array}{c}\mathbf{1}^{\text {st }} \text { Wind } \\
(\mathrm{p} . \mathrm{u})\end{array}$ & $\begin{array}{c}\mathbf{2}^{\text {nd }} \text { Wind } \\
(\mathrm{p} . \mathrm{u})\end{array}$ & $\begin{array}{c}\mathbf{3}^{\text {rd }} \text { Wind } \\
(\mathrm{p} . \mathrm{u})\end{array}$ \\
\hline No SVC & 0.02020 & 0.00810 & 0.02020 \\
\hline FST-PI & 0.00253 & 0.00112 & 0.00253 \\
\hline HPI-FLC & 0.00250 & 0.00110 & 0.00250 \\
\hline
\end{tabular}

Table 4. Settling time response comparison between systems without SVC, with FST-PI and HPI-FLC

\begin{tabular}{|l|r|r|r|}
\hline $\begin{array}{c}\text { Control } \\
\text { Type }\end{array}$ & \multicolumn{1}{|c|}{$\begin{array}{c}\mathbf{1}^{\text {st }} \text { Wind } \\
(\mathrm{s})\end{array}$} & $\begin{array}{c}\mathbf{2}^{\text {nd }} \text { Wind } \\
(\mathrm{s})\end{array}$ & \multicolumn{1}{|c|}{$\begin{array}{c}3^{\text {rd }} \text { Wind } \\
(\mathrm{s})\end{array}$} \\
\hline No SVC & - & - & - \\
\hline FST-PI & 13.426 & 19.000 & 14.242 \\
\hline HPI-FLC & 2.645 & 0.850 & 2.432 \\
\hline
\end{tabular}

is more captivating than the FST-PI based SVC. The proposed SVC obtained the voltage compensation for the system by decreasing or increasing the susceptance reference accurately, as the effect of wind speed transition. In other words, the proposed SVC could deliver the proper quantity of reactive power, whether injected or absorbed, thus making the bus voltage value close to its nominal.

The second scenario is the load changing during the simulation. Three load variations will be made to investigate the effectiveness of the proposed control algorithm. First, the load increased from 0.46 MW/0.92 MVar to 0.88 MW/1.75 Mvar. Second, the load increased from 0.46 MW/0.92 MVar to 1.07 MW/2.14 MVar. And the third variation is the decreasing of the system load from 1.07 MW/2.14 MVar to $0.46 \mathrm{MW} / 0.92 \mathrm{MVar}$. All three variations are simulated separately. The changed occurs at $70 \mathrm{~s}$.

Fig. 10 depicts the comparison of the Bus 2 voltage response during the $1^{\text {st }}, 2^{\text {nd, }}$ and $3^{\text {rd }}$ load changing. The figure compared the performance of the system without SVC, with FST-PI based SVC and the proposed HPI-FLC. According to this figure, the steady-state voltage deviation of the system could be minimized better by using HPI-FLC based SVC than FST-PI based SVC, whether the load increased or decreased. The detail numerical comparison of the performance presented in Tables 5 and 6.

From Table 5 could be explained that the proposed HPI-FLC based SVC able to minimize the steady-state voltage deviation of Bus 2 by $0.74 \%$ for the $1^{\text {st }}$ load changing, $2.65 \%$ for the $2^{\text {nd }}$ load changing and $0.95 \%$ for the $3^{\text {rd }}$ load variation. Afterward, from Table 6 could be described that the proposed control system decreased the settling time respond properly by $99.47,99.30 \%$ and $99.15 \%$ for $1^{\text {st }}, 2^{\text {nd }}$ and $3^{\text {rd }}$ load variations, respectively. 
Fig. 11 represents how the proposed HPI-FLC based SVC gives satisfying results. The HPI-FLC based SVC obtained the susceptance reference more proper, more precise and also faster than the FST-PI.

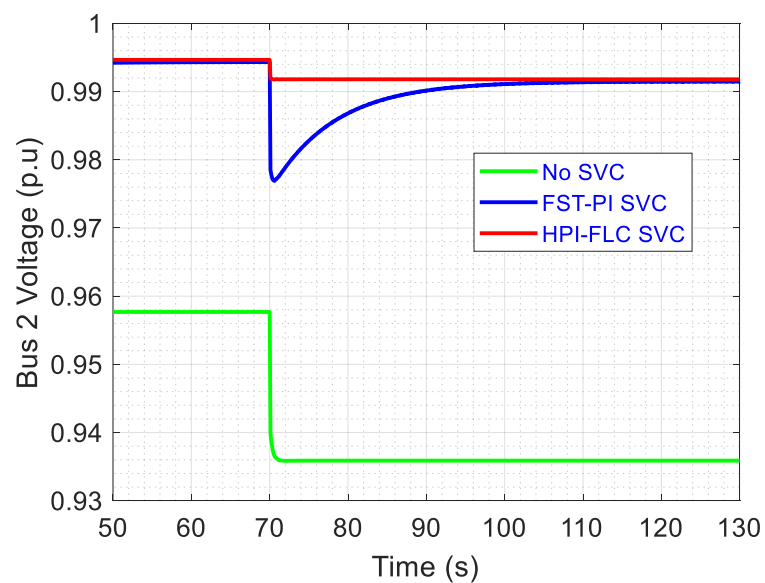

(a)

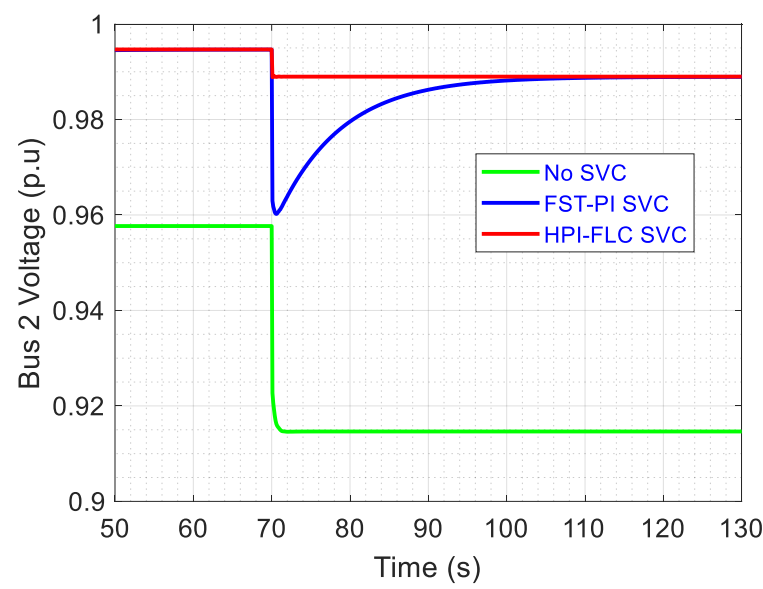

(b)

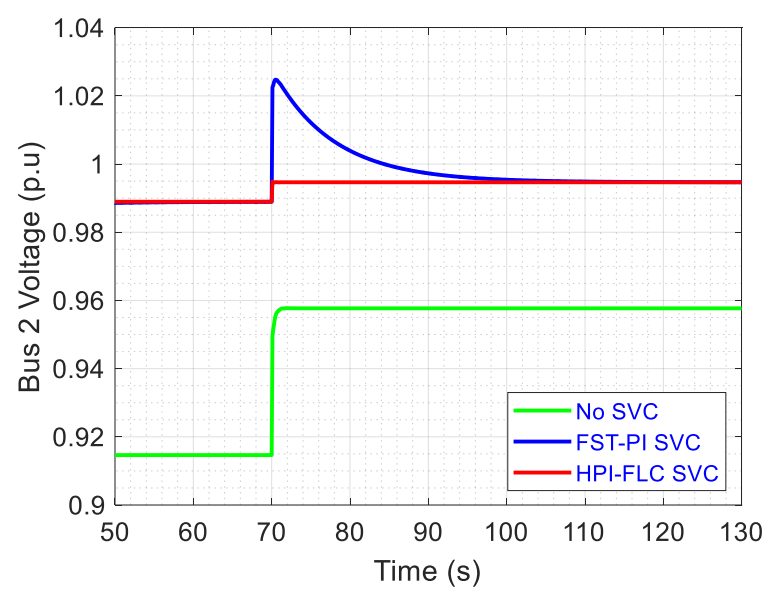

(c)

Figure. 10 Voltage response at Bus 2 for the system without SVC, with FST-PI SVC and HPI-FLC SVC: (a) with $1^{\text {st }}$ load variation, (b) with $2^{\text {nd }}$ load variation, and (c) with $3^{\text {rd }}$ load variation
The comparison of the reactive power which injected or absorbed by two investigated systems depicted in Fig. 12.

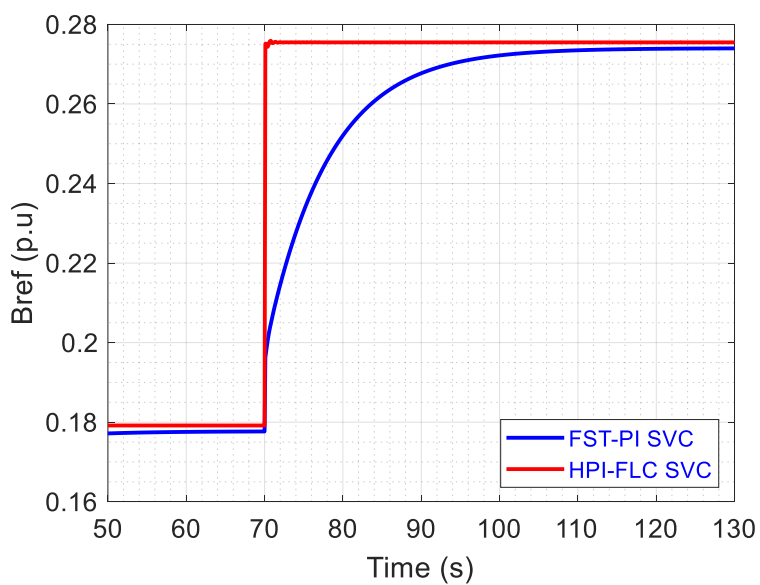

(a)

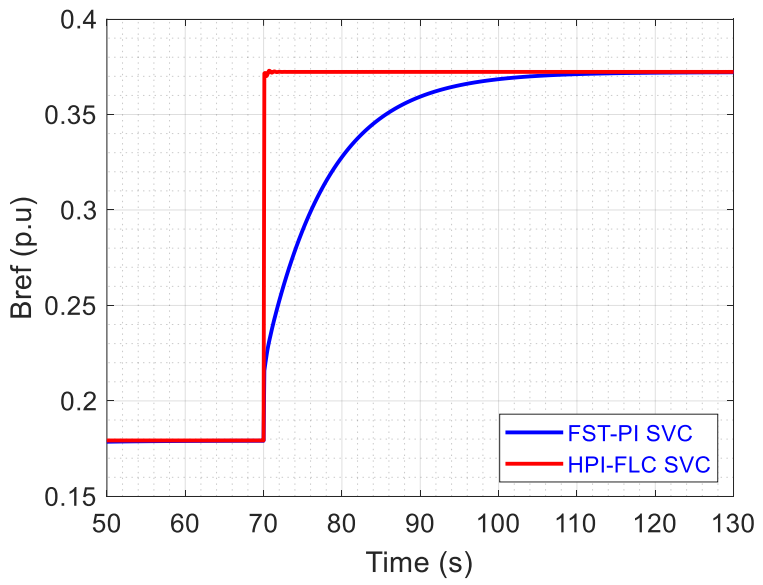

(b)

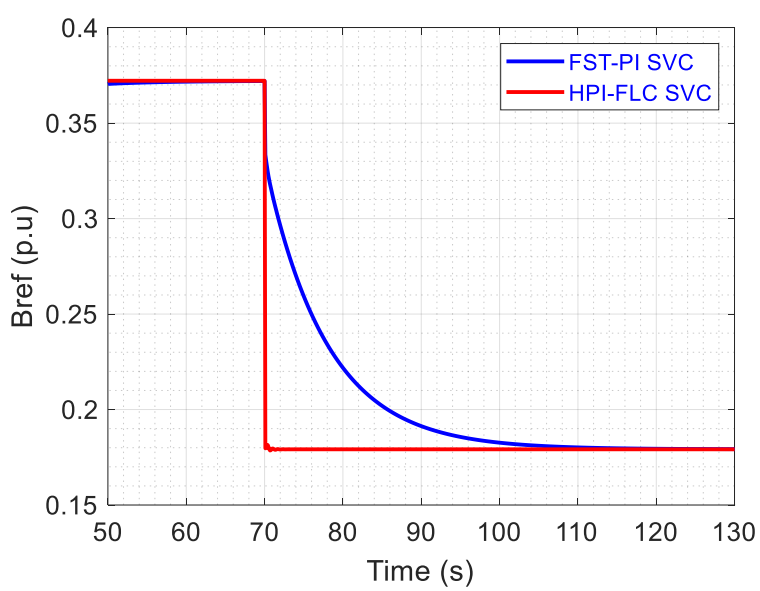

(c)

Figure. 11 Susceptance reference using FST-PI SVC and HPI-FLC SVC: (a) with $1^{\text {st }}$ load variation, (b) with $2^{\text {nd }}$ load variation, and (c) with $3^{\text {rd }}$ load variation 


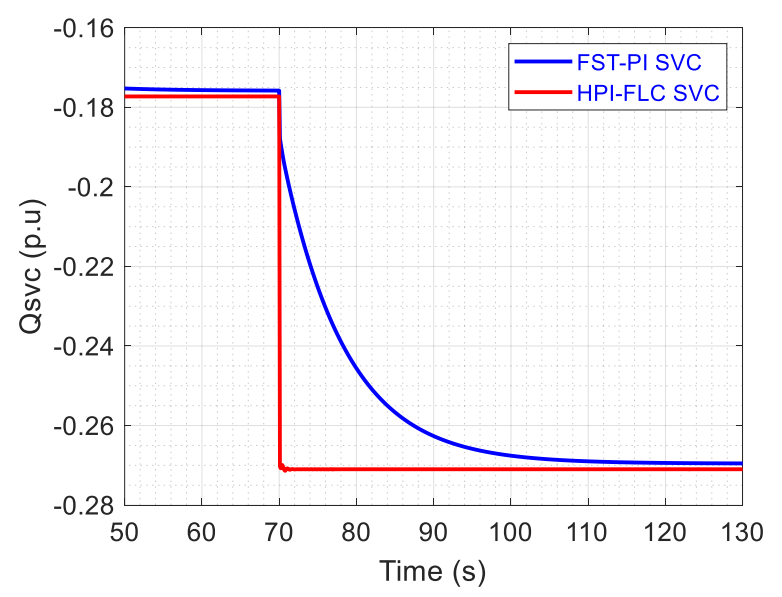

(a)

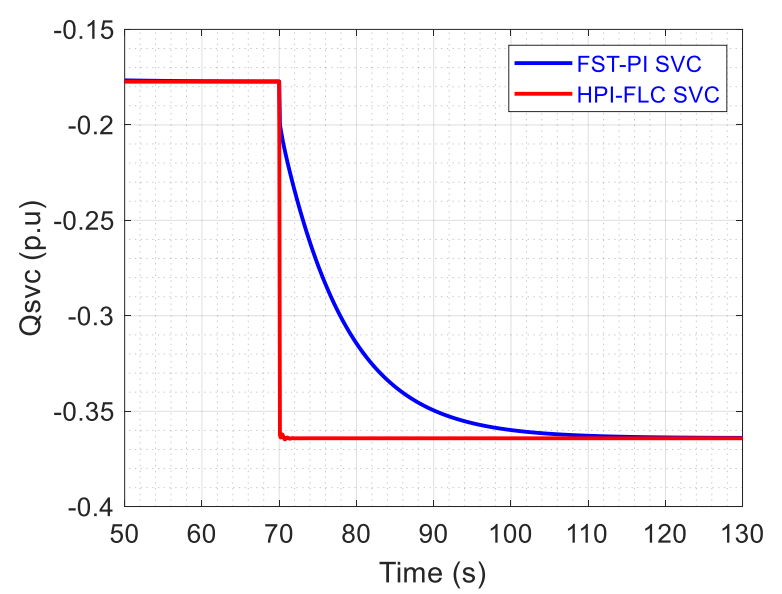

(b)

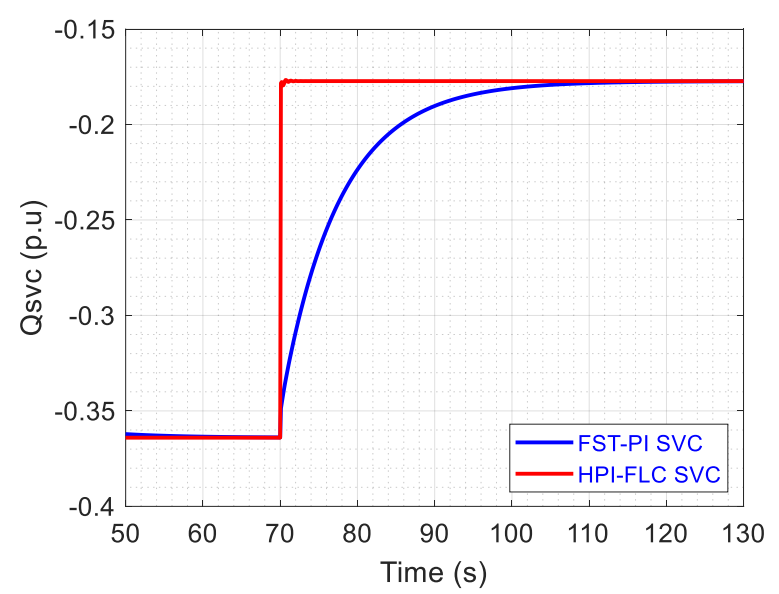

(c)

Figure. 12 Reactive power compensation using FST-PI SVC and HPI-FLC SVC: (a) with $1^{\text {st }}$ load variation, (b) with $2^{\text {nd }}$ load variation, and (c) with $3^{\text {rd }}$ load variation

Corresponding to Fig. 10, Fig. 11, and Fig. 12, the response of the system with the proposed HPI-FLC based SVC is more satisfying than the FST-PI based SVC. The proposed SVC obtained the voltage compensation for the system by decreasing or increasing the susceptance reference precisely, as the consequence of load transition. In other words, the proposed SVC could deliver the injected or absorbed reactive power properly. Hence, the bus voltage value could get closer to its nominal value.

According to the simulation results for both scenarios, on the average value, the proposed HPIFLC based SVC could minimize the steady-state voltage deviation of the system by $1.47 \%$ and the settling time of the voltage respond significantly decreased by $92.78 \%$. Therefore, the proposed HPIFLC based SVC response to the voltage fluctuation more effective and more accurate compared with the FST-PI based SVC. This is due to differences in the characteristics of each controller. Both controllers are a conventional PI-based controller. PI controller is already widely used for several applications because of its reliability. However, in order to get the proper control action, the proportional and integral gain parameter needs to be set to a proper value. The trial and error method is one of the conventional methods to obtain the proper value for the parameter. HPIFLC is the development method for the conventional PI controller. The control action of the proportional gain would be refined by the FLC that connected in cascade mode to the PI controller. Hence, the performance of the conventional PI controller could be enhanced. Unfortunately, the PI parameter should be defined first. The other PI controller development is the FST-PI controller. This control algorithm used the FLC for tuning the PI parameter. The PI parameters would be set to the proper value according to the system respond. But, this algorithm needs a longer time to respond to every change that occurs. Consequently, the settling time of the FST-PI was slower than the HPI-FLC. However, the steady-state error almost the same. Therefore, the HPI-FLC has more accuracy, reliability, and effectivity in both transient and steady-state.

Table 5. Voltage deviation comparison between systems without SVC, with FST-PI and HPI-FLC

\begin{tabular}{|l|c|c|c|}
\hline $\begin{array}{c}\text { Control } \\
\text { Type }\end{array}$ & $\begin{array}{c}\mathbf{1}^{\text {st }} \text { Wind } \\
\text { (p.u) }\end{array}$ & $\begin{array}{c}\mathbf{2}^{\text {nd }} \text { Wind } \\
\text { (p.u) }\end{array}$ & $\begin{array}{c}\mathbf{3}^{\text {rd }} \text { Wind } \\
\text { (p.u) }\end{array}$ \\
\hline No SVC & 0.06410 & 0.08540 & 0.04230 \\
\hline FST-PI & 0.00814 & 0.01130 & 0.00525 \\
\hline HPI-FLC & 0.00820 & 0.01100 & 0.00530 \\
\hline
\end{tabular}

Table 6. Settling time response comparison between systems without SVC, with FST-PI and HPI-FLC

\begin{tabular}{|l|r|r|r|}
\hline $\begin{array}{c}\text { Control } \\
\text { Type }\end{array}$ & \multicolumn{1}{|c|}{$\begin{array}{c}1^{\text {st }} \text { Wind } \\
(\mathrm{s})\end{array}$} & $\begin{array}{c}2^{\text {nd }} \text { Wind } \\
(\mathrm{s})\end{array}$ & $\begin{array}{c}3^{\text {rd }} \text { Wind } \\
(\mathrm{s})\end{array}$ \\
\hline No SVC & - & - & - \\
\hline FST-PI & 18.8510 & 19.2570 & 18.7150 \\
\hline HPI-FLC & 0.1002 & 0.1357 & 0.1589 \\
\hline
\end{tabular}




\section{Conclusion}

In this paper, the voltage regulation system with Hybrid PI-Fuzzy Logic Controller (HPI-FLC) based static var compensator (SVC) has been designed and simulated. The comparative study with FLC-based self-tuning PI (FST-PI) based SVC shows that the HPI-FLC based SVC demonstrably minimized steady-state voltage deviations and settling time voltage responds. The simulation results have described the efficacy of the proposed method for different disturbances. Future scope of this work includes fuzzy type-2 control method, the improvement of HPI-FLC by adaptive tuning based PI controller, and the implementation study of the control method to the IEEE test systems.

\section{References}

[1] M. Eckhart, M. El-Ashry, D. Hales, K. Hamilton, P. Rae, and F. Bariloche, Renewables 2018 Global Status Report, 2018.

[2] H. Pingping, D. Ming, and L. Binbin, "Study on transient stability of grid-connected large scale wind power system", In: Proc. of the $2^{\text {nd }}$ International Symposium on Power Electronics for Distributed Generation Systems, pp.621-625, 2010.

[3] M. Ma, Y.H. Liu, and D.M. Zhao, "Research on the impact of large-scale integrated wind farms on the security and stability of regional power system", In: Proc. of 2010 International Conference on Power System Technology, pp.16, 2010.

[4] M. Tesarova, R. Vykuka, and M. Kaspirek, "Impact of wind power plant operation on MV distribution grids", CIRED-Open Access Proceedings Journal, No.1, pp.724-728, 2017.

[5] E. Sáiz-Marín, E. Lobato, I. Egido, and C. Gómez-Sánchez, "Voltage control assessment of wind energy harvesting networks", IET Renewable Power Generation, Vol.8, No.8, pp.915-924, 2014.

[6] C. Wei, G. Jianpeng, P. Xiping, and L. Hengjie, "Study on voltage sag area and transient stability in power system with wind farm", In: 2014 China International Conference on Electricity Distribution, pp.437-441, 2014.

[7] Y.S. Kim, "A voltage deviation-memorizing reactive power controller for renewable energy sources", International Journal of Electrical Power \& Energy Systems, Vol.107, pp. 47-57, 2019.

[8] M. Tahir, M.E. Nassar, R. El-Shatshat, and M.M.A. Salama, "A review of Volt/Var control techniques in passive and active power distribution networks", In: Proc. of 2016 IEEE

Smart Energy Grid Engineering, pp.57-63, 2016.

[9] P. Sharma and D. Thukaram, "Reactive power and voltage control in grid connected wind farms", In: Proc. of 2012 IEEE 7th International Conference on Industrial and Information Systems, pp.1-6, 2012.

[10] H.R. Kulkarni and V.B. Virulkar, "Mitigation of flicker in a distribution-connected wind farm with STATCOM", In: Proc. of 2017 International Conference on Energy, Communication, Data Analytics and Soft Computing, pp.2208-2212, 2017.

[11] E.E.C. Moraes, S.J. De Mesquita, R.P.S. Leao, M.B.M. Neto, K.Q. Da Silva, R.M.C. Correa, H.A. dos Santos, L. Cajuaz, K.P. dos Santos, and F.R. Leite, "The application of D-STATCOM in smart distribution grid with wind power plants", In: Proc. of 2012 10th IEEE/IAS International Conference on Industry Applications, pp.1-6, 2012.

[12] V. Salehi, S. Afsharnia, and S. Kahrobaee, "Improvement of voltage stability in wind farm connection to distribution network using FACTS devices", In: Proc. of IECON 200632nd Annual Conference on IEEE Industrial Electronics, pp.4242-4247, 2006.

[13] R.M. Mathur and R.K. Varma, Thyristor Based FACTS Controllers for Electrical Transmission Systems, 1st Edition, John Wiley \& Sons Inc., United States of America, 2002.

[14] Q. Gu, A. Pandey, and S.K. Starrett, "Fuzzy logic control schemes for static VAR compensator to control system damping using global signal", Electric Power Systems Research, Vol.67, No.2, pp.115-122, 2003.

[15] H. Rezaie and M.H. Kazemi-Rahbar, "Enhancing voltage stability and LVRT capability of a wind-integrated power system using a fuzzy-based SVC", Engineering Science and Technology, an International Journal, Vol.22, No.3, pp.827-839, 2019.

[16] K.L. Lo and M.O. Sadegh, "Systematic method for the design of a full-scale fuzzy PID controller for SVC to control power system stability", IEE Proceedings - Generation, Transmission and Distribution, Vol.150, No.3, pp. 297-304, 2003.

[17] J. Wang, C. Fu, and Y. Zhang, "SVC control system based on instantaneous reactive power theory and fuzzy PID", IEEE Transactions on Industrial Electronics, Vol.55, No.4, pp.16581665, 2008.

[18] D.Z. Fang, Y. Xiaodong, T.S. Chung, and K.P. Wong, "Adaptive fuzzy-logic SVC damping controller using strategy of oscillation energy 
descent", IEEE Transactions on Power Systems, Vol.19, No.3, pp.1414-1421, 2004.

[19] H. Huang and C.-Y. Chung, "Adaptive neurofuzzy controller for static VAR compensator to damp out wind energy conversion system oscillation", IET Generation, Transmission \& Distribution, Vol.7, No.2, pp.200-207, 2013.

[20] L. Wang and D.-N. Truong, "Stability enhancement of a power system with a PMSGbased and a DFIG-based offshore wind farm using a SVC with an adaptive-network-based fuzzy inference system", IEEE Transactions on Industrial Electronics, Vol.60, No.7, pp.27992807, 2012.

[21] I.M. Ginarsa, A. Soeprijanto, and M.H. Purnomo, "Controlling chaos and voltage collapse using an ANFIS-based composite controller-static var compensator in power systems", International Journal of Electrical Power \& Energy Systems, Vol.46, pp.79-88, 2013.

[22] K. Zeb, S.U. Islam, W.U. Din, I. Khan, M. Ishfaq, T.D.C. Busarello, I. Ahmad, and H.J. Kim, "Design of Fuzzy-PI and Fuzzy-Sliding Mode Controllers for Single-Phase Two-Stages Grid-Connected Transformerless Photovoltaic Inverter", Electronics, Vol.8, No.5, pp.520, 2019.

[23] M.Z. Degefa, M. Lehtonen, R.J. Millar, A. Alahäivälä, and E. Saarijärvi, "Optimal voltage control strategies for day-ahead active distribution network operation", Electric Power Systems Research, Vol.127, pp. 41-52, 2015.

[24] I. Winarno, H. Suryoatmojo, and M. Ashari, "Hybrid-PI Fuzzy Controller Based Static Var Compensator for Voltage Regulation under Uncertain Load Conditions", Journal of Telecommunication, Electronic and Computer Engineering, Vol.9, No.2-5, pp.109-112, 2017. 